\title{
University Entrepreneurship in South Africa: Developments in Technology Transfer Practices
}

\author{
${ }^{1,2}$ Marco Alessandrini, ${ }^{1,2,3}$ Kristin Klose, ${ }^{1,2,3}$ Michael S. Pepper \\ ${ }^{1}$ Institute for Cellular and Molecular Medicine, University of Pretoria, South Africa; ${ }^{2}$ Department of \\ Immunology, Faculty of Health Sciences, University of Pretoria, South Africa; ${ }^{3}$ Unit for Advanced \\ Studies, University of Pretoria, South Africa.
}

\section{CORRESPONDANCE}

Dr Marco Alessandrini

Postal: $\quad$ PO Box 95206, Waterkloof, 0145, South Africa

Email: $\quad$ marco@mehealth.co.za

Mobile: +27-83-297-7555

\section{ABSTRACT}

Although formalised practices of technology transfer at research institutions are well established in many developed countries, these practices are still very much in their infancy in South Africa. The country is however currently focused on improving technology transfer activities and measuring the performance thereof, as exemplified by the recent implementation of a new intellectual property act. In support of the latter and in an effort to obtain an accurate overview of the status quo of technology transfer in South Africa, it was decided to evaluate organisational structures and key factors determining successful technology transfer at 13 publicly funded research institutions. It is recommended that technology transfer practices in South Africa be further strengthened through the expansion of dynamic collaborative networks and communities of practice. Crucial to these objectives is the development of appropriate metrics for measuring the successes and impact of technology transfer, taking into account the socio-economic and institutional specificities in South Africa. 


\section{KEYWORDS}

Technology transfer, technology transfer offices, intellectual property, commercialisation, Higher Education Institutions, Science Councils, South Africa, University entrepreneurship.

\section{INTRODUCTION}

The development of entrepreneurial activities at Higher Education Institutions (HEls) stems to a large extent from the implicit need for economic development and increased attention to social responsibility. To this end, and according to the World Economic Forum's Global Competitiveness Report (Schwab 2011), HEls play a vital role in increasing human capacity and efficiency, and in so doing, global competitiveness. This same report also highlights the need for sufficient investment into research and development (R\&D), the presence of high quality scientific research institutions and extensive research collaborations between HEls, government and industry.

An institutional response by many universities globally is the development of formalised technology transfer processes and, in many instances, the establishment of dedicated Technology Transfer Offices (TTOs). Similarly, in attempting to strengthen its position globally, South Africa has embraced the need for improving and exploiting the outputs of innovation by supporting processes to transform the country into a "knowledge-economy", where knowledge is the basic form of capital and where economic growth is driven by innovation (Department of Science and Technology, South Africa). In the context of this transformation, a number of 
achievements and successes are already evident with South Africa having the highest ranking in Sub-Saharan Africa (and $54^{\text {th }}$ overall out of a total of 139 economies), according to the Global Competitiveness Index (2010/11). The country's core strengths in this regard are the size of the economy by regional standards (ranked $25^{\text {th }}$ ); the accountability of private institutions (ranked $3^{\text {rd }}$ ); business sophistication (ranked $38^{\text {th }}$ ); and innovation (ranked $44^{\text {th }}$ ). More specifically, and in terms of innovation itself, South Africa has relatively sound university-industry collaboration (ranked $24^{\text {th }}$ ); good quality scientific research institutions (ranked 29 $9^{\text {th }}$ ); and a sound IP protection regime (ranked $27^{\text {th }}$ ). However, while the country has made significant progress in transforming into a knowledge economy, a number of challenges remain in terms of its R\&D and innovation capacity. Some challenges of particular importance include (1) the poor student enrolment rate of only $15 \%$ at universities; (2) the relative lack of availability of scientists and engineers; (3) the high costs of innovation; and (4) insufficient collaborative partnerships for innovation and technology commercialisation (Schwab, 2011).

In the developed world, the practice of university entrepreneurship has advanced remarkably from a management and literature point of view. This has also been influenced by factors such as the implementation of more favourable legislative conditions, such as the Bayh-Dole Act (1980) in the United States and similar policies in Europe; the rapid increase in scientific capacity and breakthrough; as well as a rise in venture capital resources (Rothaermel et al. 2007). Although the discipline has enjoyed particular attention for over three decades, the vast majority of scholarly literature on the subject has only come to the fore in the past decade (Rothaermel et 
al. 2007), indicative of a novel interest finding its feet, so to speak. South African HEls and scholars will no doubt benefit, as they are already, from such resources.

The rapid evolution of innovation and capacity development in technology transfer at South African HEls is currently a key topic of discussion. This is revealed by the commitment of government to enhance innovation potential through, among other activities, the very recent proclamation (2010) of the Intellectual Property Rights from Publicly Financed Research and Development (IPR-PFRD) Act and the establishment of the National Intellectual Property Management Office (NIPMO). Together with the dedicated interest from HEls to further develop their so-called third income stream by means of technology transfer, it is safe to say that we are entering a landmark era in South African innovation. Given these exciting developments in our country, we recently decided to evaluate the extent of IP management and technology transfer practices at local HEls, which we report herein in light of the increased focus on university entrepreneurship in our country. Moreover, such findings will contribute to the on-going efforts to collect baseline data that could inform follow-on studies designed to measure the overall impact of the IPR-PFRD Act in coming years.

\section{METHODOLOGY AND DATA COLLECTION}

In order to achieve our goal of evaluating how HEls are managing their IP, we decided to determine the status quo of TTOs at some of the most prominent South African HEls. The data was collected by means of a survey questionnaire and structured face-to-face interviews with personnel dedicated to technology transfer at each of the institutions. Although "survey fatigued" as a result of the high interest in 
the management of publicly funded IP since the drafting of the IPR-PFRD legislation, each of the institutions responded positively to the invitation to participate in the research project and all were subsequently interviewed.

The questionnaire was structured to evaluate three primary components at South African HEls and research institutions, namely (1) organisational structures; (2) factors influencing the success of technology transfer in South Africa; and (3) the current measurements of success. Following the interviews, respondents received an electronic transcript of the completed questionnaire for content verification and the inclusion of the traditionally accepted measurements of success, which included for example the number of registered invention disclosures, patent applications and patents granted.

In addition to the above, participants were invited to attend a workshop wherein the preliminary findings of the study were presented and discussed. The workshop was intended to provide a further platform for technology transfer practitioners from a range of higher education and research institutes across South Africa to discuss trends and current practices in technology transfer. The workshop was hosted by the South African Research and Innovation Management Association (SARIMA) together with the World Bank Institute (WBI) office in South Africa, who funded the study. Approximately 35 participants from universities, research institutes and other organisations, whose core mandate was to promote technology transfer, were in attendance. 


\section{ORGANISATIONAL STRUCTURES AND SERVICES OFFERED AT SOUTH AFRICAN TTOS}

Although nascent when compared internationally, technology transfer practices in South Africa have taken shape and gathered considerable momentum since 2004 when it was reported that, while a number of institutions had already developed and implemented IP policies, only three had one or more full-time employees dedicated to technology transfer and related matters (Garduño 2004). As of 2009, formal technology transfer offices existed for 11 of the 13 institutions surveyed (Table 1). Five TTOs had been in operation for at least eight years, and all appeared to have well defined technology transfer practices. However, another five TTOs had only been in operation for less than five years, indicating the rapid changes and appreciation for dedicated technology transfer practices. Of the two institutions that did not have formalised TTOs, the University of Pretoria was still in the process of establishing its official organisational structures, while Rhodes University was planning to participate in a regional collaborative effort in the Eastern Cape with the Nelson Mandela Metropolitan University (NMMU).

Table 1: $\quad$ Technology transfer at interviewed Institutions

\begin{tabular}{llc}
\hline Institution & Formal TTO & Date established \\
& & Staff number * \\
University & & 2007 \\
Nelson Mandela Metropolitan University (NMMU) & Yes & 2001 \\
North West University (NWU) & Yes & NA \\
Rhodes University (RU) & No & 1999 \\
Stellenbosch University (SU) & Yes & 1999 \\
University of Cape Town (UCT) & Yes & 2009 \\
University of the Free State (UFS) & Yes & 2005 \\
University of Johannesburg (UJ) & Yes & 2008 \\
University of KwaZulu Natal (UKZN) & Yes & NA \\
University of Pretoria (UP) & No & 2002 \\
University of the Witwatersrand (Wits) & Yes & $4(0)$ \\
Science Council & & $2(1)$ \\
Council for Scientific and Industrial Research (CSIR) & & $2(1)$ \\
Medical Research Council (MRC) & Yes & 2002 \\
Agricultural Research Council (ARC) & Yes & 2004 \\
\hline
\end{tabular}

Criteria for the selection of HEls was based on four primary factors, namely (1) that they are largely publicly funded institutions; (2) that they have a significant scientific research orientation; (3) that they have featured in previous research publications describing technology transfer in South Africa in the past five years; and (4) that they have dedicated technology transfer capabilities. ${ }^{*}=$ Total staff complement dedicated to technology transfer, with the number of temporary staff indicated in brackets. NA = not applicable. 
Proportional to the expanding development and maturation of technology transfer practices in South Africa, dedicated staff numbers (Table 1) have also been on the increase. Although this staff complement is on the increase, the total per institution is still considerably less than the 8.7 average at European institutions (Sibanda 2009). Nonetheless, these developments appear to confirm enhanced efforts towards expanding on and solidifying existing technology transfer capabilities in HEls. In terms of reporting structures, the study revealed that technology transfer personnel report directly to a dedicated research office within the institution, either through a Research Director and/or directly to the Deputy Vice Chancellor (DVC) of Research.

The modus operandi and more specific roles of technology transfer personnel varies from institution to institution. Nonetheless, the primary forms of support are largely dedicated to IP protection, followed by contract research management and, to a lesser extent, business-planning services for inventors and researchers. This reaffirms the findings in a report by Wolson (2007), where over and above the services offered directly to the inventor, the technology transfer personnel are all explicitly focused on the identification of new IP. Identification of the potential of existing IP was more of challenge though, with four of the 13 institutions indicating that they did not have sufficient capacity to do so. This may be attributable to time constraints on the part of the institutions' technology transfer practitioners and hence a focus only on IP developed from the time the technology transfer capability was established at the institution, rather than the retrospective mining of the potential IP wealth within the institution. It may therefore be argued that a significant amount of latent IP and commercialisation potential remains untapped. 
While all of the respondents confirmed the existence of a direct interface with researchers, interactions with faculty heads and students appeared to be less well developed. Even though staffing constraints were highlighted by those interviewed, there may be value in implementing improved mechanisms to tap into faculty staff resources and engaging students directly to identify a broader spectrum of IP potential. The importance of proactive engagement with the inventors cannot be emphasised enough. Sibanda (2009: 1013) reported that the most successful technology transfer efforts appear to stem from an effective and trustworthy relationship between the technology transfer professionals and the inventor. Furthermore, the trust is based on the ability of the technology transfer personnel to engage with the inventor, demonstrate empathy with the inventors' challenges, as well as being able to proactively assist the inventors to extract maximum value from their research.

\section{PERCEPTIONS AND FACTORS INFLUENCING TECHNOLOGY TRANSFER}

When asked to define technology transfer per se (Table 2), it became evident that South African universities and research institutions conceptually have a relatively broad view of technology transfer, beyond a focus on the commercialisation of IP for financial gain. In particular, the definitions ranged from "...the outflow of know-how to the outside world" to "...the translation of IP into commercialised products and services for socio-economic benefits"; and ultimately to a recognition that "...technology transfer is about more than commercialisation ... it is about taking discoveries and research outputs more generally and finding applications that are useful to humankind". Although the concepts and definitions pertaining to technology transfer in South Africa are broad and range beyond a focus on commercial 
outcomes, the actual measurements of the success of technology transfer appear to be largely focused on the commercial or revenue impact within the organisation.

Table 2: $\quad$ Technology transfer as defined by South African Higher Education Institutions and Science Councils

Definition of technology transfer

- Technology transfer refers to the management and commercialisation of IP

- Strictly speaking, technology transfer refers simply to the provision of technology and its applications to the market/society

- Technology transfer is defined as the out-flow of know-how/technology to the outside world

- The movement of technology from within the institution out to a user beneficiary

- The translation of IP into commercialised products/services for social and economic benefits

- Making research outputs available to users in the public

- The commercialisation of research

- Technology transfer can be defined by the taking of an idea through various processes, obtaining partners and ultimately resulting in commercialisation

- Technology transfer includes the discovery, protection and commercial exploitation of IP

- Industry engagement

- It is the discovery of IP, protecting of IP and exploitation of IP via licensing and company spinoffs

- To identify and bring new technology to the market

With technology transfer practices being largely in the development phase in South Africa, the country's institutions have the opportunity to introduce best practices from the more established and successful global TTOs. As described by Sandelin (2004), key ingredients for successful technology transfer includes amongst others, (1) recognising the role of the inventor as an active participant in the licensing process; (2) recognising the importance of technology transfer personnel, who are engaged to proactively evaluate inventions together with the inventor, manage the disclosure and patenting process, as well as provide a multi-directional and dynamic relationship with industry; and (3) ongoing engagement with industry through proactive and ongoing marketing and direct interaction. Indeed these key ingredients were alluded to by the South African technology transfer practitioners when describing the various success factors, impediments and challenges to technology transfer at their respective institutions (Table 3). At an institutional level, it was evident that 
recognition of policy and structural changes, together with support from top management, are vital for successful technology transfer. Although the institutions have embraced these changes, the TTOs highlighted the urgent need to employ technically skilled personnel to promote the benefits of technology transfer for both the institution and the inventor; to effectively identify the potential of early stage technologies and previous IP; and to monitor and persist in the process of delivering a commercialised product. A poor IP pipeline and a lack of seed funding were also mentioned amongst the impediments.

Table 3: $\quad$ Factors influencing effective technology transfer at South African HEls

\section{Success factors}

- $\quad$ policies and work environment that promotes entrepreneurship and innovation

- $\quad$ support from institutional top management

- clear IP policies

- well established technology transfer offices

- dedicated champions to deliver the products of intellectual property appropriately

- $\quad$ sufficient incentives for people with the necessary know-how to facilitate technology transfer

Impediments to technology transfer

- lack of awareness [amongst researchers] of the benefits of commercialising research

- $\quad$ capacity to identify early stage technologies

- $\quad$ insufficient human resource capacity to manage and monitor technology transfer activities

- $\quad$ inadequate interaction with entrepreneurs and industry partners

- a lack of seed funding

- $\quad$ poor intellectual property pipeline

\section{Challenges}

- Assisting researchers in being able to identify when data becomes IP (particularly in light of the IPR-PFRD Act)

- Increasing IP awareness at the institutions

- Training of researchers and students to identify IP

- Establishing the best means of interaction with researchers and students

- The extent to which technology transfer personnel should be proactive in seeking out potential IP

- Understanding the capacity requirements for monitoring the influx of new IP (as may required by the IPR-PFRD Act)

- $\quad$ Establishing the responsibilities in performing patent searches 
A number of comments emerged from the WBI/SARIMA Workshop with regard to key challenges for technology transfer personnel (Table 3), and in particular, the importance of raising the awareness of the potential value of IP protection and management among researchers. Generally, it was felt that if the ultimate aim of technology transfer is to commercialise the institution's IP, whether for financial gain or a combination of broader economic and social impacts, a top-down approach would be most beneficial by promoting awareness of IP among the Executive of the respective institutions.

Given the challenges facing the establishment and effective management of TTOs at South African institutions, the option for a more collaborative approach was also considered. However, the establishment of a regional TTO, with the purpose of pooling and sharing resources to enhance the capabilities of individual TTO functions, was not supported by all institutions. Of the five institutions that were in support of this model, one survey respondent explicitly confirmed a preference for utilising the technology transfer expertise and capabilities of a partner institution. Five of the 13 respondents were not in favour of a regional TTO approach, whilst three were undecided. This lack of specific preference was reconfirmed at the WBI/SARIMA Workshop, wherein the "Bordeaux TTO model" was mentioned by some of the participants as a successful approach to combining the TTOs of several universities in a region so as to pool the expertise and resources of technology transfer staff. Some workshop participants were however not in favour of this model and expressed the concern that a centralised TTO would impact negatively on the inter-personal relations between TTO personnel and researchers, a factor that is critical for success in this area. In contrast, others were indeed in favour of a 
collaborative approach, which was testament to the current formation of a regional TTO in the Eastern Cape that includes four local institutions and is managed from the Nelson Mandela Metropolitan University (NMMU).

\section{INSTITUTIONAL POLICIES AND MEASUREMENTS OF SUCCESS}

In terms of the IP policies in South Africa during the period of this study and prior to the promulgation of the IPR-PFRD, the majority of institutions where "university oriented" (Garduño 2004), meaning that patent rights are owned by the university and that these in turn place obligations on staff and researchers to report any new inventions to their institutions. In this scenario, the institutions secure the rights to the IP as well as the authority to license inventions to third parties or to dispose of the rights to third parties. Where the universities and NIPMO choose not to commercialise the IP, the rights are returned to the inventor. In contrast, at universities that had "researcher oriented" (Garduño 2004) IP policies before the IPRPFRD Act, the rights to the IP developed by students and researchers were vested predominantly with the inventor. When comparing the benefit sharing of IP at the 13 surveyed institutions (Figure 1) before the implementation of the IPR-PFRD Act, the majority of the institutions were "institution oriented", as all of the respondents indicated a minimum of $30 \%$ benefit to the institution, with only three institutions offering greater than $30 \%$ to the inventor. 
Figure 1: $\quad$ Royalty distribution at the surveyed South African HEls

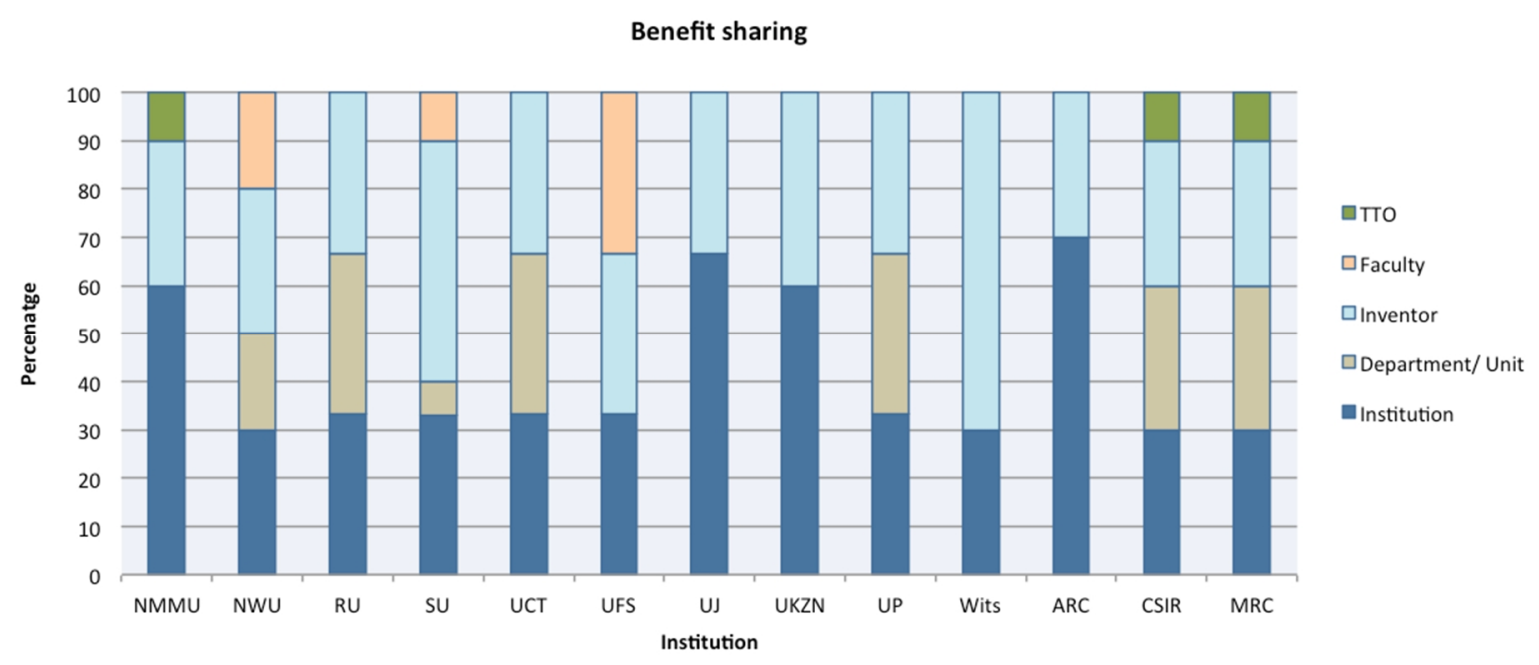

ARC = Agricultural Research Council; CSIR = Council for Scientific and Industrial Research; HEls = Higher Education Institutions; MRC = Medical Research Council; NMMU = Nelson Mandela Metropolitan University; NWU = North West University; RU = Rhodes University; SU = Stellenbosch University; TTO = Technology transfer office; UCT = University of Cape Town; UFS = University of the Free State; UJ = University of Johannesburg; UKZN = University of KwaZulu Natal; UP = University of Pretoria; WIts = University of the Witwatersrand.

When measuring the traditional indicators of success over a 5 year period from 2004 to 2008 (Figure 2 and Appendix One), it was noted that invention disclosures increased significantly from 40 in 2004 to a total of 123 in 2008 (Figure 2A). In addition and of the 11 who provided their feedback, several more institutions started reporting invention disclosures as a measurement of success over this same period, increasing from four institutions in 2004 to a total of nine institutions by 2007. The timing of these increases may bear testimony to the increased attention that is being paid to technology transfer as a result of the establishment of dedicated technology transfer capacities, including personnel and IP policies. This supports the report by Sibanda (2009: 1013) that indicated a correlation between patent activity and the existence of IP policies and appropriate institutional arrangements for the identification, management and commercialisation of intellectual property. 
Figure 2: $\quad$ Intellectual property outputs at South Africa Higher Education Institutions
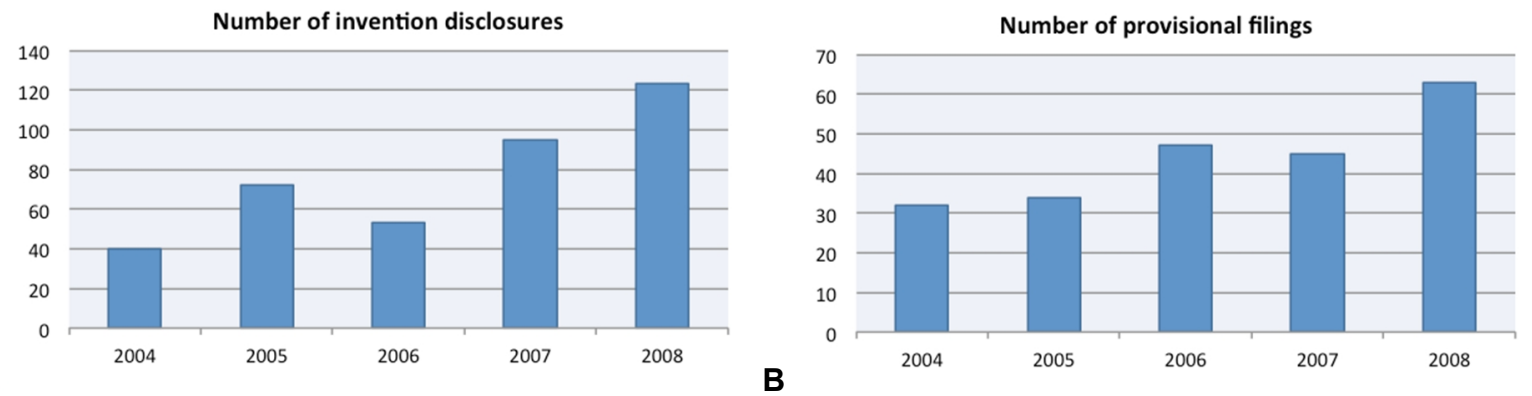

A
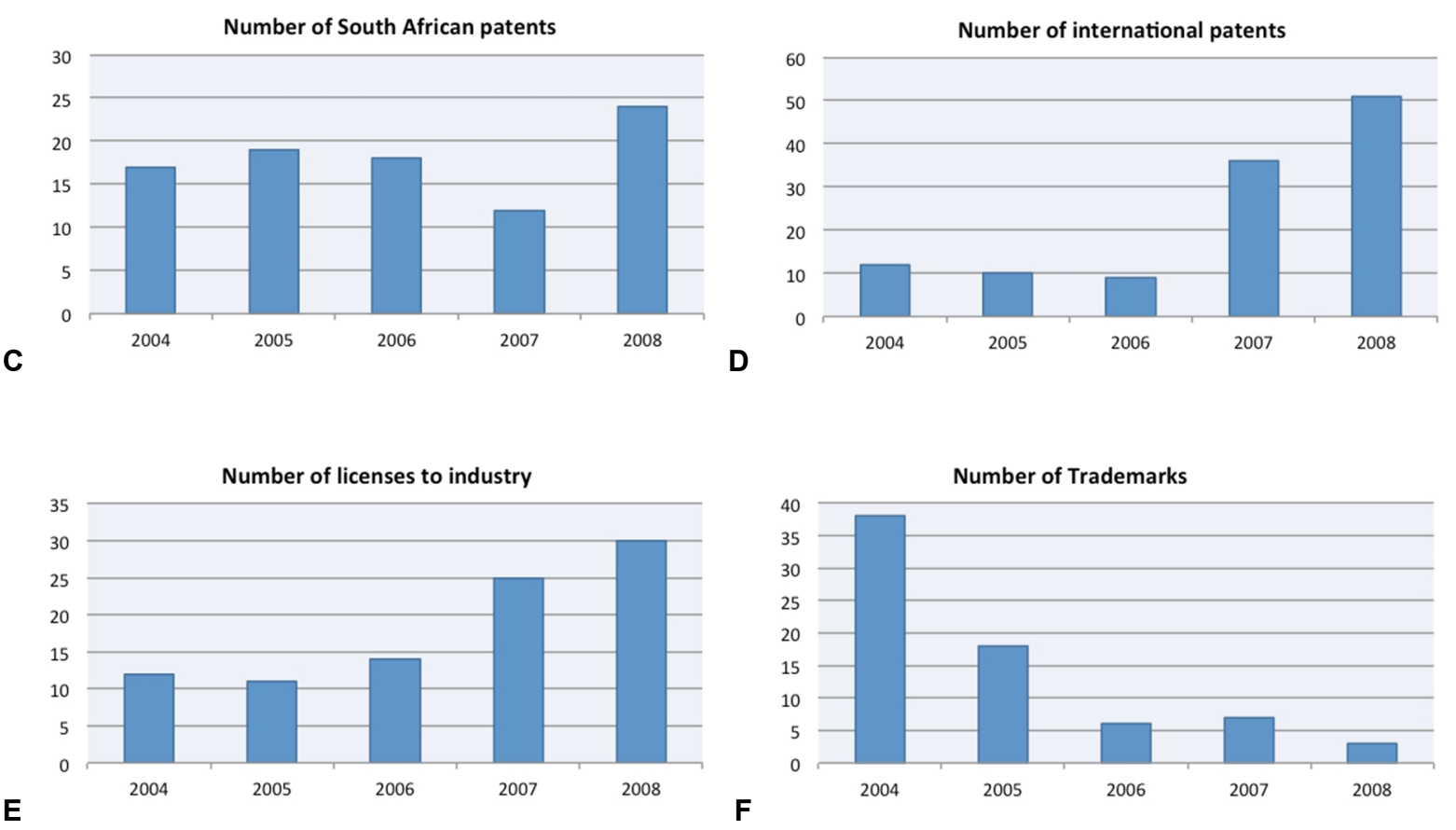

Despite the increases in invention disclosures, the conversion rate of potential IP into patentable, and later commercialisable technologies, appears to remain modest. Even though there was more than three-fold increase in invention disclosures as reported by the institutions from 2004 to 2008 , the number of provisional filings only doubled from 32 in 2004 to 63 in 2008 (Figure 2B). Similarly, there also appeared to be an upward trend in the number of South African patents (Figures 2C). However, these numbers are still very modest with only 24 South Africa patents being registered in 2008. The most striking improvement is observed in the trend for international patents, where a marked increase in the number of registrations was 
reported in the years 2007 and 2008 (Figure 2D). In terms of the potential for further industry partnerships and collaboration, the overall rate of licensing to industry has steadily increased from 12 licenses in 2004 to 30 in 2008 (Figure 2E). Although the data for individual institutions is not shown, it should be noted that the vast proportion of international patents and licences to industry were contributed primarily by no more than three of the institutions surveyed. Given the South African government's recent focus on improving IP output, it is expected that the latter trend will indeed shift to have almost all institutions making significant contributions to the national IP pool.

All institutions showed little to no indication of the pursuit of other intellectual property protection options, including for example trademarks, which showed a marked decrease from 38 in 2004 to only 3 in 2008 (Figure 2F). The reasons for the lack of interest in this form of IP were not determined. It may however be argued that a possible explanation for the focus on patent registration rather than the other IP protection options, is that the most active sectors involved in the technology transfer activities of participating institutions are those engaged in research fields that are the most 'patentable', namely the health and medical sciences, engineering and natural sciences, followed by agricultural sciences and ICT (Figure 3). 

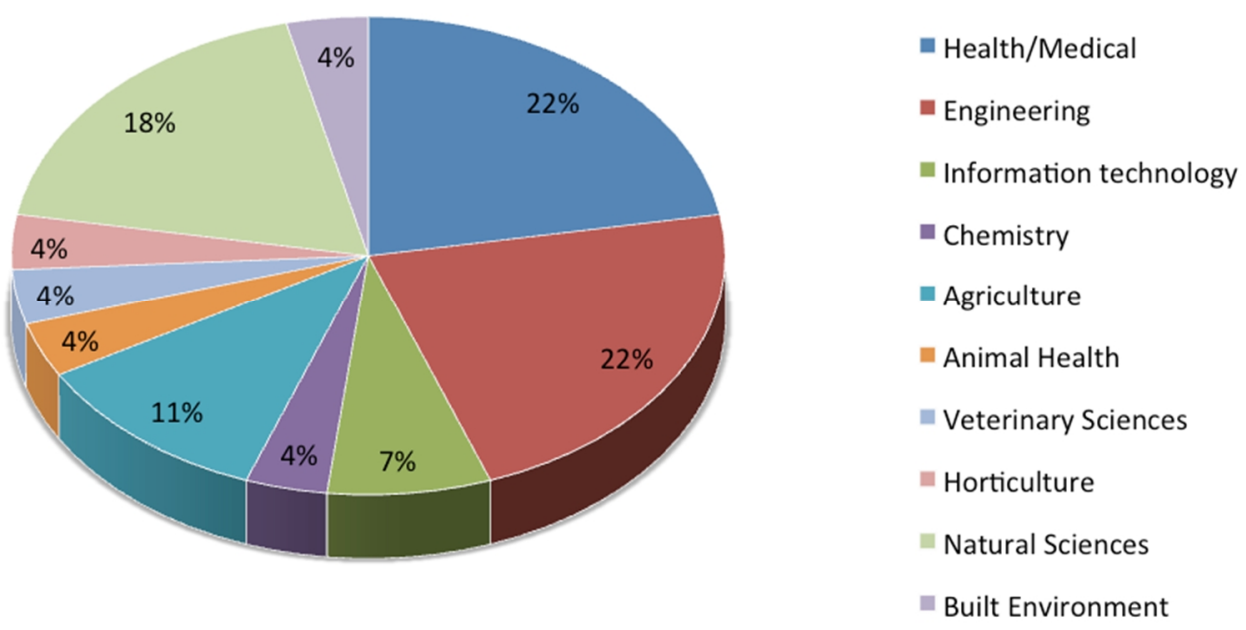

These findings were consistent with those of the 2007/8 and 2008/9 National R\&D Survey, which revealed that the largest share of South Africa's R\&D expenditure is directed towards the engineering sciences $(22.5 \%$ and $24.4 \%$ in $2007 / 8$ and $2008 / 9$ respectively), natural sciences $(20.5 \%$ and $20.6 \%)$, medical sciences and health sciences (14\% and $14.8 \%$ ) as well as ICT (at $14 \%$ and $13.1 \%$ ). Furthermore, this was also consistent with findings of Sibanda (2009: 1013) who reported in his review of patenting activity that a concentration of patents occurred in classes that may be linked to the life sciences, biotechnology and ICT.

Internationally, while innovation is linked to economic growth, the actual measurement of innovation, and by extension, the efficacy and value derived through the processes of technology transfer, "remains rudimentary" (Advisory Committee on Measuring Innovation in the $21^{\text {st }}$ Century Economy 2008). For example, patent data, including patent applications, granted national and international patents, as well as trademarks, have for a long time been widely used as a measure of success in 
innovation in general. According to Lubango and Pouris (2007: 27), there is compelling evidence that patents and patent applications can be used to investigate technological change, economic growth and the relationship between the two. However, although patents are good indicators of new technology creation, they do not measure the economic value of these technologies. Furthermore, since not all new innovations are patented and since patents differ greatly in their economic impact, patents may not be the most appropriate measure of innovation output (Pakes and Griliches 1980), particularly in a developing world setting. In this context, HEls, research institute administrators and technology transfer officials are under increasing pressure to demonstrate a positive economic contribution in return for the resources devoted to the technology transfer activities of their offices.

In line with the growing international call for diversification in the measurements of innovation and technology transfer activities in particular, there is a lack of agreement among South African institutions regarding the metrics that should be used to measure success. It was unanimously accepted that the current units of measure, namely patents and commercialisation revenues, are not adequate measures of success of technology transfer activities, particularly in a developing world setting. The commercialisation of IP may additionally be evaluated on the basis of (1) job creation; (2) accessible technology based products and services; (3) reduction in poverty and mortality; (4) other measures of social impact on communities; and (5) the long-term financial benefits to the country as a whole.

According to Kruss (2006: 24), there has been a growing emphasis for universities to convert their IP into patents, as there is a perception that South African HEls have a 
dismal record concerning international patents. Although Boschoff and Mouton (2003) only reported data from 1997-2001, it was indicated that the majority of South African patents are individually owned and universities do not feature at all on the list of top ten South African patenting organisations. This is further supported by Sibanda (2009: 1013), who confirmed the generally low rate of patenting by South African institutions at both local and international levels.

Anecdotal evidence from the study further suggests that the combination of underresourced TTOs and low levels of awareness have contributed to the low number invention disclosures and patenting rates and also to the low conversion of patents to commercial products or licenses. This, together with increasing pressure to generate a "third income stream" at HEls in the wake of reduced government subsidies, may adversely impact on the focus of the technology transfer offices by diverting focus from getting IP into the market place to that of generating income. Finally, the low patenting rates can also be attributed to the fact that a large proportion of research at the universities in particular has not been carried out with commercialisation in mind.

\section{CONCLUSION AND RECOMMENDATIONS}

Although deemed to be in its infancy, the focus on formalising technology transfer functions at South African HEls has been steadily gaining momentum over the past 6 years. While it is not yet clear what the impact of the IPR-PFRD Act and its requirement for HEls to better structure their technology transfer activities through the creation of TTOs will be, semi-formalised technology transfer structures have already begun to take shape. However, even though IP policies and dedicated technology transfer personnel are in place at all of the institutions surveyed, few 
appeared to be adequately resourced to perform the broad spectrum of services, particularly the mining of existing IP, that are required of a TTO.

It is widely agreed that the current measurements of technology transfer outputs are not only inappropriately defined, but also do not take into account the national impact of the activities of the technology transfer personnel. Instead of an exclusive focus on, for example, the number of registered patents and income from license agreements, efficacy of technology transfer function could be expressed in terms of parameters such as the social impact on communities, jobs created and reduction in poverty, all of which can be equated to long term financial benefits to the country as a whole. The key measurables of an institution's technology transfer efforts will be refined with the IPR-PFRD Act in mind and will be elaborated in collaboration with NIPMO, in order to ensure these are appropriately tailored for the needs of South Africa and possibly on a larger scale for the developing world.

It is recommended that a more collaborative effort be initiated not only amongst the institutions, but also with regulatory authorities. In support of this recommendation, there are a handful of the more established TTOs in South Africa that have been in operation for approximately a decade, while several other HEls (including the universities of technology) are in the process of developing their organisational and procedural structures. Collaborations to streamline these processes would certainly offer a time- and cost-effective solution for these institutions. Furthermore, continued collaboration through communities of practice would provide a forum to share experiences, improve processes, and showcase and exploit the potential of institutional IP. 


\section{ACKNOWLEDGEMENTS}

We would like to express our gratitude to the survey participants, the South African Research and Innovation Management Association (SARIMA), and the World Bank Institute for funding the study.

\section{REFERENCES}

Advisory Committee on Measuring Innovation in the $21^{\text {st }}$ Century Economy (2008). Innovation Measurement: Tracking the State of Innovation in the American Economy, a Report to the Secretary of Commerce, accessed at http://www.innovationmetrics.gov/Innovation\%20Measurement\%2001-08.pdf on 16 March 2009 Boshoff N, Mouton J (2003). Science policy indicators, in: Human Resources Development Review, Education, Employment and Skills in South Africa, Kraak, B., Perold, H., (eds). Cape Town, HSRC Press and East Lansing, Michigan State University Press.

Department of Science and Technology, South Africa. Ten Year Innovation Plan, 2008-2018, accessed at http://www.dst.gov.za/publications-policies/strategies-reports/The\%20TenYear\%20Plan\%20for\%20Science\%20and\%20Technology.pdf on 8 March 2011.

Garduño E (2004). South African University Technology Transfer: A Comparative Analysis. International Intellectual Property Institute (IIPI), 906 Pennsylvania Avenue, SE, Washington DC.

Kruss G (2006). Working Partnerships: The challenge of creating mutual benefit for academics and industry. Perspectives in Education 24(3), 1-13.

Lubango L, Pouris A (2007). Industry work experience and inventive capacity of South African academic researchers. Technovation 27(12), 788-796.

Pakes A, Griliches Z (1980). Patents and R\&D at the Firm Level: A First Look. NBER Working Papers 0561, National Bureau of Economic Research, Inc.

Rothermael., F.T.S., Agung, S., Jiang, L., 2007. University entrepreneurship: a taxonomy of the literature, Industrial and Corporate Change 16, 691-791. 
Sandelin J (2004). Success Factors in University Technology Transfer through Patenting and Licensing, accessed at http://otl.stanford.edu/about/documents/JSSuccessGuidelines.pdf on 10 February 2009.

Schwab K (2011). The Global Competitiveness Report 2010-2011. World Economic Forum, Geneva, Switzerland.

Sibanda M (2009). Intellectual Property, Commercialisation and Institutional Arrangements at South African Public Research Institutions, in: The Economics of Intellectual Property in South Africa. World Intellectual Property Organisation (WIPO) 1013(E).

Wolson R (2007). Technology Transfer in South African Public Research Institutions, in: Krattiger, A., Mahoney, R.T., Nelson, L., et al. (eds), Intellectual Property Management in Health and Agricultural Innovation: A Handbook of Best Practices. MIHR: Oxford, UK and PIPRA, Davis, USA. 


\section{APPENDIX ONE: Intellectual property metrics provided by South African TTOs}

The presented metric data is representative of that provided by 11 of the 13 institutions interviewed during the WBI study.

\begin{tabular}{|c|c|c|c|c|c|c|c|c|}
\hline Category & Year & Total & Min & Max & Average & $\begin{array}{l}\text { Standard } \\
\text { deviation }\end{array}$ & $\begin{array}{l}\text { Data points } \\
\text { provided }\end{array}$ & $\begin{array}{l}\text { Data not } \\
\text { available }\end{array}$ \\
\hline \multirow{5}{*}{$\begin{array}{l}\text { Invention } \\
\text { Disclosures }\end{array}$} & 2004 & 40 & 5 & 20 & 10.0 & 6.9 & 4 & 7 \\
\hline & 2005 & 72 & 3 & 34 & 18.0 & 12.8 & 4 & 7 \\
\hline & 2006 & 53 & 1 & 16 & 7.6 & 5.2 & 7 & 4 \\
\hline & 2007 & 95 & 3 & 35 & 10.6 & 9.5 & 9 & 2 \\
\hline & 2008 & 123 & 2 & 49 & 15.4 & 16.4 & 8 & 3 \\
\hline \multicolumn{2}{|c|}{ OVERALL } & 383 & 1 & 49 & 12.0 & 11.1 & 32 & 23 \\
\hline \multirow{5}{*}{$\begin{array}{l}\text { Provisional } \\
\text { Filings }\end{array}$} & 2004 & 32 & 1 & 10 & 4.0 & 3.3 & 8 & 3 \\
\hline & 2005 & 34 & 0 & 12 & 5.7 & 5.2 & 6 & 5 \\
\hline & 2006 & 47 & 1 & 23 & 6.7 & 7.7 & 7 & 4 \\
\hline & 2007 & 45 & 0 & 22 & 5.6 & 6.8 & 8 & 3 \\
\hline & 2008 & 63 & 1 & 27 & 7.9 & 9.0 & 8 & 3 \\
\hline \multicolumn{2}{|c|}{ OVERALL } & 221 & 0 & 27 & 6.0 & 6.5 & 37 & 18 \\
\hline \multirow{5}{*}{$\begin{array}{l}\text { SA Patents } \\
\text { (granted) }\end{array}$} & 2004 & 17 & 0 & 7 & 2.1 & 2.1 & 8 & 3 \\
\hline & 2005 & 19 & 0 & 7 & 2.4 & 2.2 & 8 & 3 \\
\hline & 2006 & 18 & 0 & 6 & 2.6 & 2.1 & 7 & 4 \\
\hline & 2007 & 12 & 0 & 3 & 1.3 & 1.0 & 9 & 2 \\
\hline & 2008 & 24 & 0 & 6 & 2.7 & 2.2 & 9 & 2 \\
\hline \multicolumn{2}{|c|}{ OVERALL } & 90 & 0 & 7 & 2.2 & 1.9 & 41 & 14 \\
\hline \multirow{5}{*}{$\begin{array}{l}\text { International } \\
\text { Patents }\end{array}$} & 2004 & 12 & 0 & 7 & 2.4 & 2.7 & 5 & 6 \\
\hline & 2005 & 10 & 0 & 7 & 1.7 & 2.7 & 6 & 5 \\
\hline & 2006 & 9 & 0 & 3 & 1.3 & 1.0 & 7 & 4 \\
\hline & 2007 & 36 & 0 & 12 & 5.1 & 5.6 & 7 & 4 \\
\hline & 2008 & 51 & 0 & 35 & 7.3 & 12.5 & 7 & 4 \\
\hline \multicolumn{2}{|c|}{ OVERALL } & 118 & 0 & 35 & 3.7 & 6.6 & 32 & 23 \\
\hline \multirow{5}{*}{$\begin{array}{l}\text { Licenses to } \\
\text { industry }\end{array}$} & 2004 & 12 & 2 & 7 & 4.0 & 2.6 & 3 & 8 \\
\hline & 2005 & 11 & 3 & 5 & 3.7 & 1.2 & 3 & 8 \\
\hline & 2006 & 14 & 0 & 5 & 2.3 & 1.8 & 6 & 5 \\
\hline & 2007 & 25 & 0 & 17 & 3.6 & 6.0 & 7 & 4 \\
\hline & 2008 & 30 & 0 & 17 & 6.0 & 6.8 & 5 & 6 \\
\hline \multicolumn{2}{|c|}{ OVERALL } & 92 & 0 & 17 & 3.8 & 4.5 & 24 & 31 \\
\hline \multirow{5}{*}{ Trademarks } & 2004 & 38 & 1 & 31 & 9.5 & 14.5 & 4 & 7 \\
\hline & 2005 & 18 & 0 & 12 & 3.6 & 5.0 & 5 & 6 \\
\hline & 2006 & 6 & 0 & 4 & 1.0 & 1.5 & 6 & 5 \\
\hline & 2007 & 7 & 0 & 6 & 1.2 & 2.4 & 6 & 5 \\
\hline & 2008 & 3 & 0 & 3 & 0.6 & 1.3 & 5 & 6 \\
\hline \multicolumn{2}{|c|}{ OVERALL } & 72 & 0 & 31 & 2.8 & 6.4 & 26 & 29 \\
\hline
\end{tabular}

